NASA Technical Memorandum 106318

AIAA-93-4401

\title{
Noise Levels From a Model Turbofan Engine With Simulated Noise Control Measures Applied
}

David G. Hall

Sverdrup Technology, Inc.

Lewis Research Center Group

Brook Park, Ohio

and

Richard P. Woodward

Lewis Research Center

Cleveland, Ohio

Prepared for the

15th AIAA Aeroacoustics Conference

sponsored by the American Institute of Aeronautics and Astronautics

Long Beach, California, October 25-27, 1993 
$-$ 


\title{
NOISE LEVELS FROM A MODEL TURBOFAN ENGINE WITH SIMULATED NOISE CONTROL MEASURES APPLIED
}

\author{
David G. Hall* \\ Sverdrup Technology Inc., Brook Park, OH 44142 \\ and \\ Richard P. Woodward* \\ NASA Lewis Research Center, Cleveland, OH 44135
}

\begin{abstract}
This paper presents a study of estimated full-scale noise levels based on measured levels from the Advanced Ducted Propeller (ADP) sub-scale model. Testing of this model was performed in the NASA Lewis Low Speed Anechoic Wind Tunnel at a simulated takeoff condition of Mach 0.2. Effective Perceived Noise Level (EPNL) estimates for the baseline configuration are documented in this report, and used as the control case in a study of the potential benefits of two categories of noise control. The effect of active noise control is evaluated by artificially removing various rotor-stator interaction tones. Passive noise control is simulated by applying a notch filter to the wind tunnel data. Cases with both techniques are included to evaluate hybrid active-passive noise control. The results for EPNL values are approximate because the original source data was limited in bandwidth and in sideline angular coverage. The main emphasis is on comparisons between the baseline and configurations with simulated noise control measures.
\end{abstract}

\section{Introduction}

Acoustic testing of the Advanced Ducted Propeller (ADP) model was conducted in the NASA Lewis Low Speed Anechoic Wind Tunnel between October 1990 and April 1991. A previous report, published by Woodward et al., documents the far field results for Sound Pressure Level (SPL).' The present study uses these far field SPL results as the raw data for calculating Effective Perceived Noise Level (EPNL) estimates from a large-scale ADP in the baseline configuration. The aircraft engine design community has shown considerable interest in applying active noise control measures to turbofan engines. ${ }^{2}$ This paper explores the potential benefits of active noise control in a typical nextgeneration ducted fan by selectively removing the tone noise from the ADP data via digital filtering and analyzing the improvement in estimated EPNL. In addition, passive noise control measures are simulated by applying various broadband attenuation curves to the control case data. Combined active-passive noise control measures are also evaluated. The results with tone removal showed only modest improvements in EPNL, mainly because of the unique design of the ADP, which was carefully configured to minimize tone noise. Its attributes included low tip speed, large rotor-stator axial spacing and cutoff of the fundamental rotor-stator interaction tone via careful selection of the number of stator vanes. It is likely that active noise control would show a greater potential for EPNL reduction if it was applied to a current generation turbofan engine.

\section{Apparatus}

\section{Anechoic Wind Tunnel}

The NASA Lewis 9- by 15 - $\mathrm{ft}$ Anechoic Wind Tunnel is located in the low-speed return leg of the 8- by 6-ft wind tunnel. The maximum airspeed in the test section is slightly over Mach 0.20, providing a takeoff/approach test environment. The tunnel acoustic treatment provides anechoic conditions down to a frequency of $250 \mathrm{~Hz}$, which is lower than the frequency of any propeller acoustic tones expected from the ADP model.

\section{Acoustic Instrumentation}

The acoustic data used in the present study were acquired using a sideline traversing microphone probe, as shown in Fig. 1. This probe was equipped with two $0.64 \mathrm{~cm}$ ( 0.25 in) condenser microphones. Data for this report were acquired using the outermost microphone, which was located $167 \mathrm{~cm}$ ( $66 \mathrm{in})$ from the propeller centerline. The probe could survey a sideline of approximately 20 to $140^{\circ}$ relative to the plane of the propeller. The probe was programmed to move with approximately constant angular velocity relative to the model. Each traverse took approximately $180 \mathrm{sec}$ to complete.

\section{ADP Model}

Detailed design parameters for the ADP model are documented in Ref. 1 . The more relevant information is repeated here for convenience. The model was configured with 16 blades and either 22 or 40 stator vanes. The combination of 22 vanes and 16 blades generates rotor-

*Member AIAA 
stator interaction tones at the blade passing frequency (BPF) that propagate out of the duct. ${ }^{3}$ The interaction tone at BPF that is generated with the 40 -vane stator does not propagate (cut-off effect). The model was operated at the takeoff blade setting angle of $-11^{\circ}$ relative to cruise, with fan speeds of $84 \%, 96 \%, 102 \%$, and $107 \%$ relative to the design speed for the cases used in the present report. This provided subsonic tip speeds in all cases. Data were taken at windmill conditions as well, to provide an estimate of tunnel background level. The ADP installation provided a capability to rotate the model in the horizontal plane to provide a nonzero angle of attack relative to tunnel airflow; however, all data in this report were derived from cases with zero angle of attack. The model was driven by a compressed air turbine. There was no provision to simulate the noise effects of the core engine that would be present in a flight-configured engine. The model was configured with three different inlet geometries during NASA Lewis testing. The distance from the rotor stacking line to the inlet highlight was $12.09 \mathrm{~cm}$ (4.76 in) for the "short" inlet, $21.03 \mathrm{~cm}(8.28 \mathrm{in})$ for the "midlength" inlet, and $26.14 \mathrm{~cm}$ (10.29 in) for the "long" inlet.

Most data used in this report were collected with the "short" spinner configuration. Data for the case with the 40vane stator and short inlet include some cases with the "plug," or "long," spinner. A sketch of the inlet and spinner configuration is shown in Fig. 2.

\section{Procedure}

\section{Source Data}

During wind tunnel testing, the traversing microphone signal was recorded using a digital spectrum analyzer. Each traverse produced 52 narrow-band spectra covering the range from 0 to $20 \mathrm{kHz}$ with a resolution of $64 \mathrm{~Hz}$. The upper bound of $20 \mathrm{kHz}$ was chosen because it was the maximum capability of the available analyzer. In addition, this bandwidth permitted analysis of the 1st through the 6th harmonic of the BPF tone for the ADP model. Each spectrum was the result of 12 frequency domain spectral averages. A probe position signal was digitized and used to calculate the sideline angle for each of the 52 averaged spectra.

\section{Post-Processing}

A flow chart of the data processing operation used to produce results for this report is shown in Fig. 3. The following operations were performed.

(1) Convert the spectrum analyzer data file from volts to units of pressure.

(2) Perform a tunnel background correction by subtracting a spectrum taken under windmill conditions from the corresponding spectrum taken with the model under power.
(3) Apply simulated noise control, if desired.

(4) Convert results to sound pressure level, in decibels relative to $20 \mu \mathrm{Pa}$.

(5) Correct for the microphone frequency response.

(6) Correct for the frequency response of the "Bullet Nose" microphone windscreen.

(7) Apply a Doppler shift to the spectral data, with the direction and magnitude of the shift calculated from sideline angle and tunnel airspeed.

(8) Transform each spectrum to a standard radius of $30.5 \mathrm{~cm}$ (12 in), compensating for tunnel convection effects, spherical spreading, and atmospheric absorption.

(9) Apply frequency and amplitude scaling to account for the model scale. The model fan diameter was $43.82 \mathrm{~cm}$ (17.25 in). The projected full-scale fan radius is $300.36 \mathrm{~cm}$ (118.25 in). The frequency shift scale factor is thus equal to $1: 6.855$. Amplitude scaling was done using the square of this value to account for the increase in thrust (proportional to inlet area).

(10) Transform to a level flight path with flyover height of $1500 \mathrm{ft}$, accounting for spherical spreading and atmospheric absorption under Federal Aviation Administration (FAA) standard day conditions. This provided a singleengine simulation at a flight condition of Mach 0.2 .

(11) Synthesize 1/3-octave power levels from the narrow band spectra.

(12) Using the full set of 52 measurements, compute noy weighted, 1/3-octave spectra, perceived noise level, tone corrected (PNLT) versus time curves, and EPNL estimates.

The simulated noise control option in step three was performed in a variety of ways. Active noise control was simulated by selectively removing the BPF tone or one of its harmonics down to the adjacent broadband level (see Fig. 4. Broadband-only results were computed by removing the BPF tone and all of its harmonics. The effect of an exhaust duct liner was simulated by applying a broadband attenuation curve to all of the model-scale spectra with sideline angles greater than $100^{\circ}$. The maximum attenuation was $3 \mathrm{~dB}$ at the center frequency (see Fig. 5). This attenuation level is relatively low because the goal of this study was to model an exhaust-duct-only liner with minimum system performance penalties such as added weight and increased drag. The use of an inlet duct liner was not modeled for similar reasons.

Three values of liner center frequency were evaluated; the first was at BPF for $100 \%$ speed $(440 \mathrm{~Hz}$ at full scale, $3040 \mathrm{~Hz}$ at model scale), the second at 2 times the BPF $(880 \mathrm{~Hz}$ at full scale, $6080 \mathrm{~Hz}$ at model scale), and the third 
at a full-scale frequency of $1470 \mathrm{~Hz}(10 \mathrm{kHz}$ at model scale). The methods of Ref. 4 were used to evaluate the approximate physical dimensions of these liners. The required length to height ratios $(\mathrm{L} / \mathrm{H})$ at full scale were estimated to be 0.67 (440 Hz liner), $1.0(880 \mathrm{~Hz}$ Liner) and $1.67(1470 \mathrm{~Hz}$ liner). These values are consistent with the available space in the full-scale exhaust duct, which is expected to have a height of $81.3 \mathrm{~cm}$ (32 in) and a length of $152.4 \mathrm{~cm}(60 \mathrm{in})$ for an $\mathrm{L} / \mathrm{H}$ of 1.875 .

\section{EPNL Estimate}

The computer program used to perform postprocessing step 12 was written to comply with the requirements of Ref. 5, including tone correction. The EPNL results are approximations because the bandwidth of the spectral data from the wind tunnel tests was limited to $20 \mathrm{kHz}$. This translates to a full-scale frequency of $2918 \mathrm{~Hz}$. Ignoring the effect of Doppler shift, the highest 1/3-octave frequency band that can be computed from this data is $2000 \mathrm{~Hz}$. The FAA standard requires computation of 1/3octave bands from $50 \mathrm{~Hz}$ to $10 \mathrm{kHz}$. Initially, it was thought that the sound energy in the model-scale data above $20 \mathrm{kHz}$ might be significant. Two test cases were analyzed, using experimental data from 0 to $20 \mathrm{kHz}$ plus broadband levels estimated via linear interpolation in the range from 20 to $80 \mathrm{kHz}$. This provided full-scale data up to the $10 \mathrm{kHz}$ 1/3-octave band. The first test case used the baseline data (no simulated noise control). The second test case had all of the BPF-related tones removed via digital filtering. The relative change in EPNL was approximately equal to the change observed when these two cases were run using the 0 to $20 \mathrm{kHz}$ (model scale) spectra.

In addition, the track traverse system was limited to sideline angles of approximately 20 to $140^{\circ}$. The FAA standard requires an SPL difference of $10 \mathrm{~dB}$ in PNLT between the peak value and the minimum at each end of the flyover. This was not feasible with the ADP data, since the traversing microphone probe did not move far enough to achieve a 10-dB dropoff at both ends in some cases. A typical plot of PNLT versus time is shown in Fig. 6.

The single-engine EPNL numbers listed below cannot be used to predict the compliance of an ADP-equipped aircraft with FAA noise regulations accurately. In addition to the limitations noted above, the ADP model did not include any provisions to simulate the noise of the core engine or to account for multiengine effects. The intention of this paper is to assess the noise output of the baseline ADP model to its output with various noise-reduction schemes in place. For that purpose, all EPNL estimates will be presented in decibels relative to a common, predefined reference level.
Table 1 - EPNL results in relative levels.

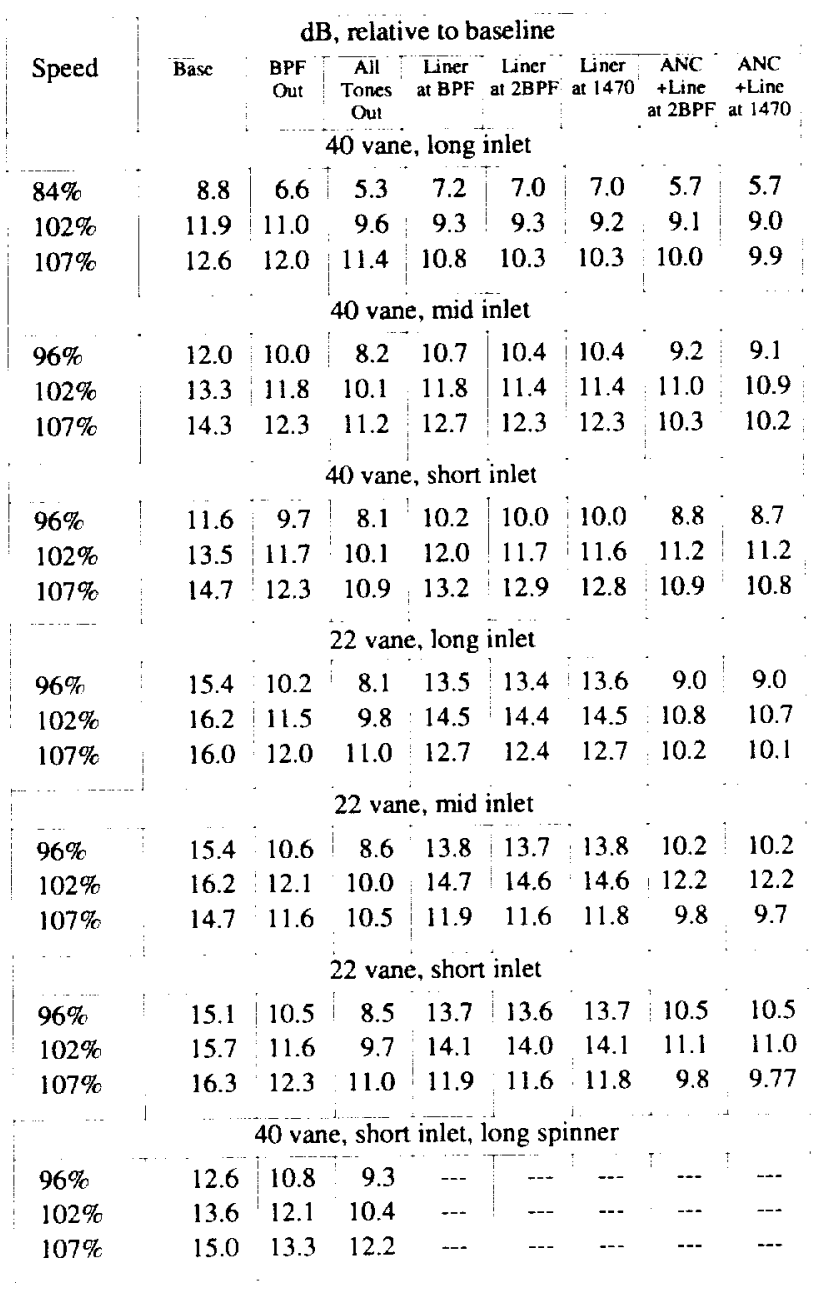

\section{Analysis of Results}

The results of this study are shown in Table 1. The column labeled "Base" in this table shows the EPNL estimate for the baseline model configuration. The column labeled "BPF Out" shows the results when the BPF tone is removed as shown in Fig. 4. The column labeled "All Tones Out" shows the effect of removing the BPF tone and all of its harmonics. The intent is to show the relative importance of broadband noise to the EPNL values. The column labeled "Liner at BPF" shows the effect of placing a simulated exhaust duct liner tuned to the frequency corresponding to BPF at $100 \%$ of the design speed. The column labeled "Liner at 2BPF" shows the effect of a simulated exhaust duct liner tuned to twice the BPF. The column labeled "Liner at 1470" shows the effect of an exhaust duct liner tuned to suppress broadband noise. The value of 1470 is a full-scale frequency, and was chosen by examining a variety of model-scale, 1/3-octave spectra computed with all 
tones removed, which commonly peaked near $10 \mathrm{kHz}$ (see Fig. $7(\mathrm{a})$ ). A full-scale frequency of $1470 \mathrm{~Hz}$ corresponds to a model-scale frequency of $10 \mathrm{kHz}$. A full-scale, noyweighted spectrum, computed with all BPF-related tones removed, is shown in Fig. 7(b).

The last two columns in Table 1 show the effect of hybrid active-passive noise control. The data in the column labeled "ANC + Line at $2 \mathrm{BPF}$ " were computed by removing the BPF tone via digital filtering and applying a liner model tuned to twice BPF. The column labeled "ANC + Liner at 1470 " shows the results when the BPF tone is suppressed using digital filtering and the liner is tuned to suppress broadband noise as described earlier.

Some interesting observations may be made, based on the data in Table 1. Figures 8 (a) to 8(c) show the effect of active noise control on the model configured with the 40 vane stator and short spinner. EPNL reductions of $2 \mathrm{~dB}$ are typical when the BPF is removed. This number is large when one considers that the 40-vane model was designed to provide cutoff of the rotor-stator interaction tone at BPF. The reason for this reduction was the presence of residual BPF tone noise. Reference 6 provides a discussion of this residual noise, which was attributed to irregularities in the casing tip treatment. For a device with a more fully suppressed BPF tone, it is likely that active noise control operating at BPF would provide very little EPNL reduction.

Results for the model configuration with the 40-vane stator, short inlet, and long spinner are shown in Fig. 8(d). EPNL reductions with BPF tone removal are similar to those observed with this inlet and the short spinner (Fig. 8(c)).

The effect of BPF tone removal on the 22-vane model is shown in Figs. 8(e) to $8(\mathrm{~g})$ for the long, medium, and short inlet cases, respectively. Here, the EPNL reduction is more pronounced when the BPF is removed, with typical improvements in the 4 to $5 \mathrm{~dB}$ range. This is to be expected, since the BPF tone is cut-on in the 22-vane model.

The effects of the three exhaust duct liner models are shown in Figs. 9(a) to 9(c) for the 40-vane model, and in Figs. $9(\mathrm{~d})$ to $9(f)$ for the 22-vane model. These figures show a typical reduction in EPNL of 2 to $3 \mathrm{~dB}$, with the largest reductions occurring at the highest fan speeds. The center frequency of the liner model seems to have little effect on the noise suppression performance. If an exhaust duct liner is to be added to the production ADP, the choice of center frequency probably will be made based on mechanical considerations. The liner that is optimized for BPF suppression would provide the smallest $\mathrm{L} / \mathrm{H}$ ratio, but the greatest thickness. The liner that is optimized for broadband suppression would have the least thickness, but the largest $\mathrm{L} / \mathrm{H}$. If one assumes that the production engine has a stator vane count that provides cutoff of the BPF tone, and a modified casing tip treatment to remove the residual BPF noise, then the liner that is optimized for BPF suppression probably would not be chosen.

The relative merits of active control of the BPF tone versus the hybrid active-passive approach are shown in Figs. 10(a) to 10 (c) for the 40 -vane model and in Figs. 10 (d) to $10(\mathrm{f})$ for the 22-vane model. These figures show the results when the BPF tone is removed via digital filtering and when two alternate exhaust duct liners are applied. The first liner was tuned to twice BPF and the second was tuned for broadband suppression $(1470 \mathrm{~Hz}$ at model scale). In general, the use of the hybrid approach provides 1 to $2 \mathrm{~dB}$ of additional EPNL reduction over the active-only approach. The effect is most pronounced at the higher fan speeds. The improvement with hybrid noise control versus the baseline levels was approximately 3 to $4 \mathrm{~dB}$ with the 40 -vane configurations and 5 to $6 \mathrm{~dB}$ with the 22-vane configurations. Thus, the hybrid active-passive approach offers only a modest improvement over the approach using active noise control alone.

The relative merits of each simulated approach to noise control are shown in Fig. 11(a) for the 40-vane model and in Fig. 11 (b) for the 22-vane model. Data from Table 1 are plotted for the midlength inlet at $102 \%$ speed in each case. It is interesting that in the 40-vane case, the application of active noise control offers approximately the same benefit as the use of an exhaust duct liner. In the 22 -vane case, suppression of the BPF tone is superior to the use of the exhaust duct liner.

\section{Broadband Results}

One of the noise control goals in modern high bypass turbofan engines is to reduce the broadband content. Table 1 includes results that show the residual EPNL left when all BPF-related tones are removed. Figures 12(a) to 12(d) show these results in graphic form for the 40 -vane model configurations. The 22-vane results are shown in Figs. 12(e) to $12(\mathrm{~g})$. Typical results for the 40 -vane cases show 3 to $4 \mathrm{~dB}$ of EPNL reduction. The improvement in cases with 22-vane stators is approximately 5 to $6 \mathrm{~dB}$. This indicates that some form of broadband noise suppression will be required before further gains can be made in noise reduction.

The data in Table 1 may be used to infer several things about the mechanisms generating broadband noise in the ADP model. The EPNL estimates provide a means to determine, roughly, which sources are most important in formulating a broadband noise control strategy. Much additional research is needed in this area.

An attempt was made to evaluate the relative importance of three possible sources of broadband noise using the EPNL results from this test. The sources evaluated were 
(1) Interaction between turbulent rotor blade wakes and the stator vanes

(2) Interaction between the rotating blades and the boundary layer on the spinner

(3) Interaction between the rotating blades and the boundary layer on the duct wall

The results suggest that none of these sources was a dominant factor in the broadband noise generated. It is suspected that a fourth source (rotor-alone broadband noise) may have been dominant.

An interesting evaluation of the first source was made by comparing the broadband EPNL estimates (Table 1, column labeled "All Tones Out") for the 40-vane configuration model and for the 22-vane model, each with the same inlet configuration (short spinner). Table 1 shows that the levels are roughly the same. As documented in Ref. 1, the midspan chord length of the 40-vane stator was $3.73 \mathrm{~cm}$ (1.47 in). This parameter was increased to $6.76 \mathrm{~cm}$ (2.66 in) in the 22-vane model. Two parameters that are known to influence the broadband noise output are the total surface area in the stator airfoils and the stator chord length.' In this test, the surface area remained approximately constant while the total number of stator vanes increased from 22 to 40 . This change should have little or no effect on broadband output. The longer chord length in the 22-vane configuration was expected to cause a decrease in broadband noise. This was not observed. The lack of change in broadband level with changes in stator vane configuration suggests that the rotor wake-stator vane interaction is not a dominant broadband source in the ADP.

An evaluation of the second source, rotor/spinnerboundary-layer interaction was also made. Data are included in Table 1 for the 40-vane, short inlet case for two spinner configurations (long and short). It is assumed that the boundary layer on the long spinner was considerably thicker than the boundary layer present with the short spinner. EPNL estimates with "all tones out" for the long spinner case were slightly higher at all speeds versus the levels seen with the short spinner. The magnitude of the difference was small, on the order of $1 \mathrm{~dB}$, but it was higher at all three speeds. At first, this was interpreted as evidence that the rotor/spinner-boundary-layer interaction may be a significant noise source. The narrow-band, as-measured spectra that were used to compute the EPNL values were checked to verify that the excess noise in the long-spinner case was broadband in nature. An example is shown in Fig. 13. Analysis of this figure (and others not shown here) indicates that the increased EPNL values with the long spinner were caused by the presence of extraneous tones. The frequency of these tones did not correspond to any harmonic of the blade passing frequency, and so they were not removed in the digital filter processing that yielded the EPNL data for "all tones out". The extraneous tones did occur with frequencies corresponding to multiples of the fan shaft speed. The source of these tones is not known with certainty, but an airflow disturbance on the spinner is suspected. The general conclusion is that the rotor/spinnerboundary-layer interaction was not a significant factor in the broadband noise generated by this model.

The contribution of the third source, interaction between the rotating blades and the boundary layer on the duct wall, was studied from Table 1 by comparing the broadband EPNL estimates for different inlet lengths with the number of stator vanes held constant. The thickness of the duct wall boundary layer is expected to be greatest with the long inlet and least with the short inlet. If this source is a major factor in overall broadband noise, then the "all tones out" data should show higher EPNL estimates for longer inlet lengths. This trend was not observed. If we take the results for $107 \%$ speed, Table 1 shows that the EPNL estimates for the 40-vane cases (excluding the long spinner data) varied by only $0.5 \mathrm{~dB}$ over the three inlet lengths. The variation was again $0.5 \mathrm{~dB}$ for the 22-vane cases.

None of the available data was suitable for evaluating the importance of the fourth source, broadband, rotor-alone noise. The data that were available indicate that none of the other postulated sources was dominant. This suggests, by process of elimination, that the fourth source may be dominant. Additional research is needed in this area.

\section{Concluding Remarks}

This report has presented EPNL estimates for the ADP model based on wind tunnel data taken in the NASA Lewis Low Speed Anechoic Wind Tunnel. The baseline results were used to study the effect of adding simulated active-passive noise control measures. In general, the suppression of the BPF tone yielded only modest noise reduction. This was due in part to the design of the ADP itself, since it included several features intended to suppress tone noise: low tip speed, large rotor-stator spacing, and cutoff BPF tone with the 40 -vane stator. It is likely that current-generation turbofans, with more dominant tone noise, would benefit more from the application of active noise control than the ADP. Even so, the simulation results with the ADP model indicate a limit on the maximum benefit available from tone noise reduction. Once the tones are gone, the broadband noise becomes the dominant source.

The following conclusions were reached regarding the effectiveness of noise control strategies and the nature of the dominant noise source.

(1) The reduction in estimated EPNL that was realized by fully suppressing the BPF tone via active noise control 
was approximately 2 to $3 \mathrm{~dB}$ with the cutoff stator and 4 to $5 \mathrm{~dB}$ with the cuton stator.

(2) Results obtained using a simulated passive exhaust duct liner showed that the EPNL reduction for the 40-vane model was equivalent to the reduction obtained by suppressing the BPF via active noise control. With the 22 -vane model, active noise control offered more improvement than the duct liner approach.

(3) Hybrid noise control simulations (with the BPF tone removed via active noise control and an exhaust duct liner tuned for broadband suppression) yielded 1 to $2 \mathrm{~dB}$ of additional improvement in estimated EPNL over the case with BPF tone removal alone. Results for the cuton and cutoff stator were equivalent.

4) Three broadband noise sources were evaluated based on the EPNL estimates with all BPF-related tones removed to attempt to identify the dominant source mechanism. None of these sources (rotor-wake/stator-vane interaction, rotor/ duct-wall-boundary-layer interaction and rotor/spinnerboundary-layer interaction) appeared to dominate. This suggests that rotor-alone broadband noise may be the most significant source. Additional research is needed in this area.

\section{$\underline{\text { References }}$}

1. Woodward, R.P., Bock, L.A., Heidelberg, L.J. and Hall, D.G.,"Far-Field Noise and Internal Modes From a Ducted Propeller at Simulated Takeoff Conditions," NASA TM-105369, 1992. (Also AIAA Paper 92 0371, 1992).

2. Thomas, R., Burdesso, R., Fuller, C. and O'Brien, W.. "Active Control of Fan Noise From a Turbofan Engine," AIAA Paper 93-0598, 1993.

3. Tyler, J.M., and Sofrin, T.G.,"Axial Flow Compressor Noise Studies," SAE Transactions, Vol. 70, 1962 pp. 309-332.

4. Minner, G.L., and Rice, E.J., "Computer Method for Design of Acoustic Liners for Turbofan Engines," NASA TM X-3317, 1976.

5. Noise Standards: Aircraft Type and Airworthiness Certification. Aircraft Noise Measurement. Federal Aviation Regulations, Vol. III, Pt. 36, App. A, Sect. 36.2, 1969.

6. Heidelberg, L., and Hall, D.,"Acoustic Mode Measurements in the Inlet of a Model Turbofan Using a Continuously Rotating Rake," AIAA Paper 93-0598, 1993.

7. Glegg, S.,"Broadband Noise From Subsonic Ducted Propfans," Presented at the 1993 International Noise and Vibration Control Conference, St. Petersburg, Russia, 1993.

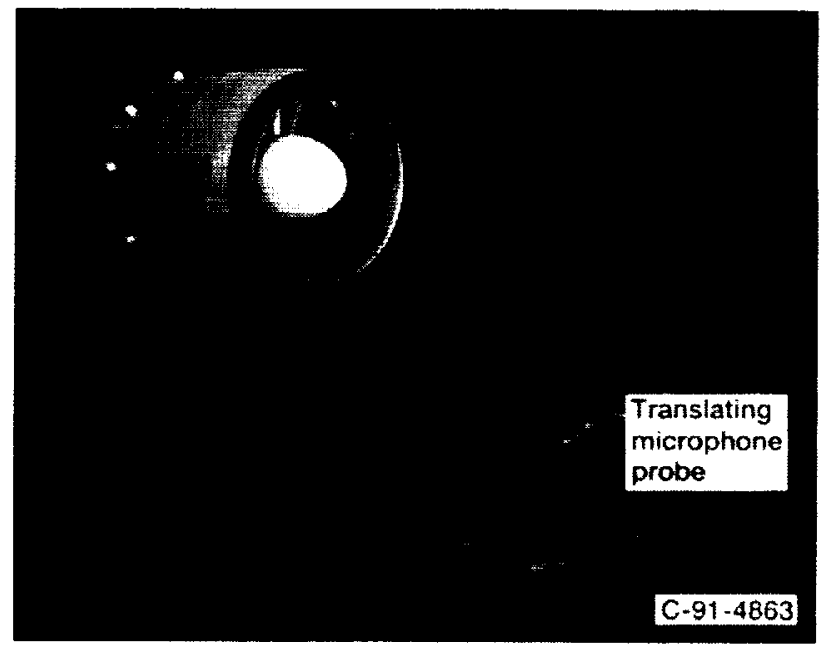

Figure 1 - Advanced ducted propeller model installed in the 9- by 15-ft Anechoic Wind Tunnel, shown with translating microphone probe.

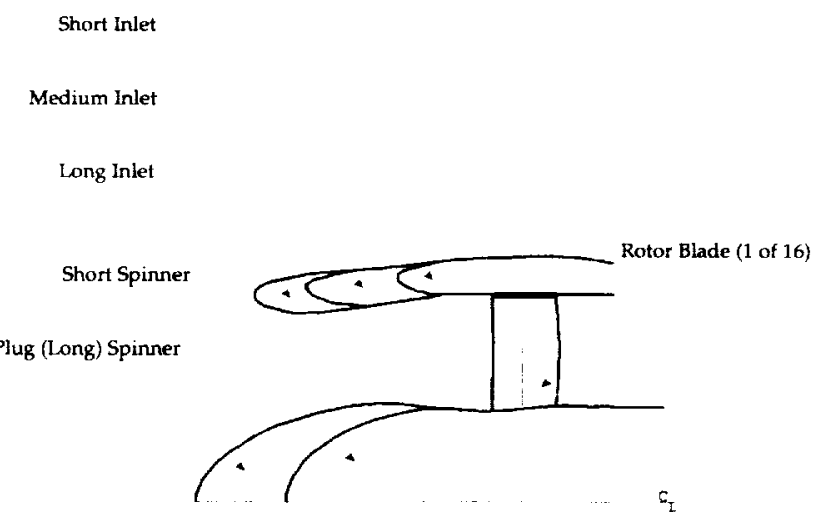

Figure 2 - Inlet and spinner configurations in the ADP model. 


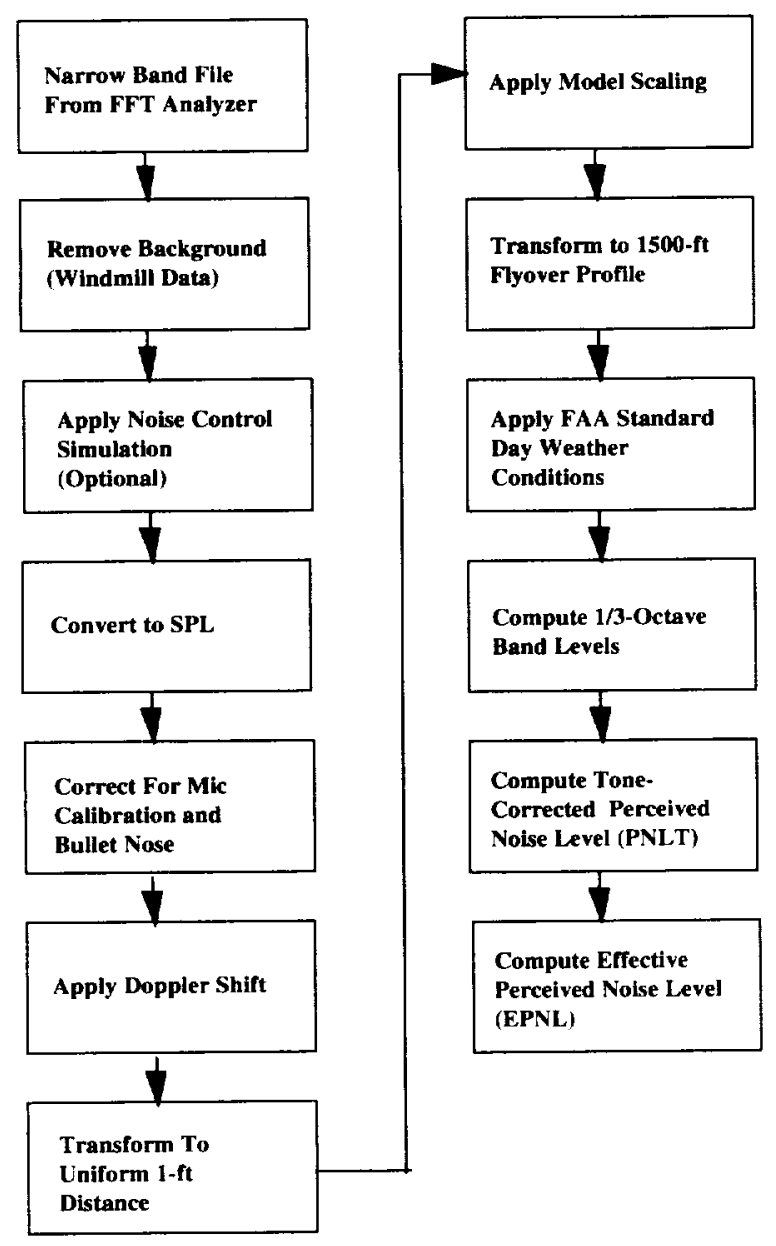

Figure 3 - Data processing flowchart.

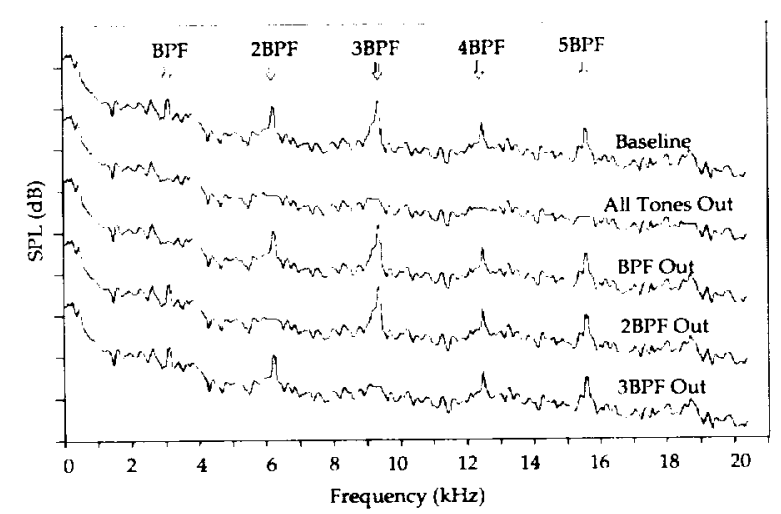

Figure 4 - Simulated active noise control, waterfall plot.

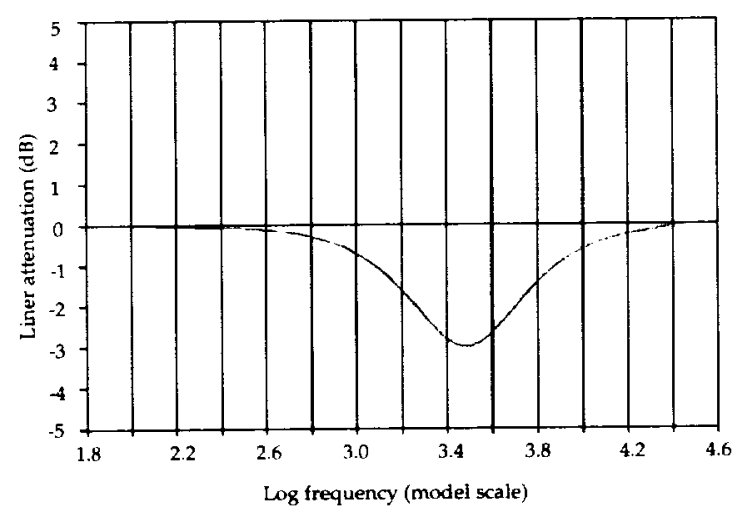

Figure 5 - Attenuation of the exhaust duct liner model versus frequency.

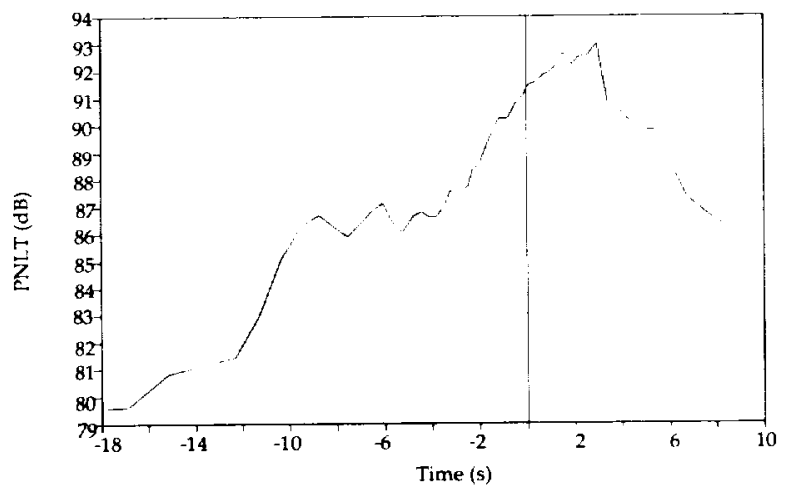

Figure 6 - Typical flyover noise profile. Data taken from the 40 -vane model operating at $107 \%$ speed.

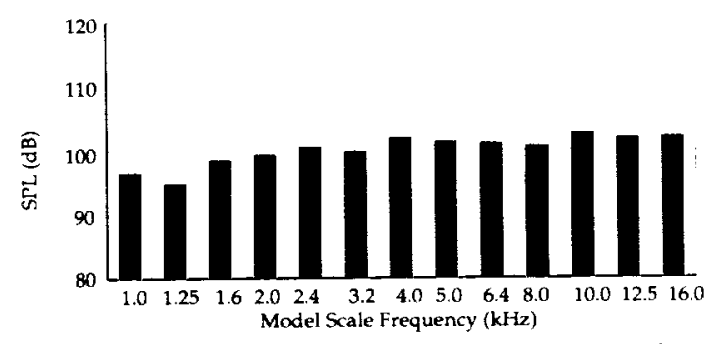

a. 1/3-octave spectrum, as measured scale.

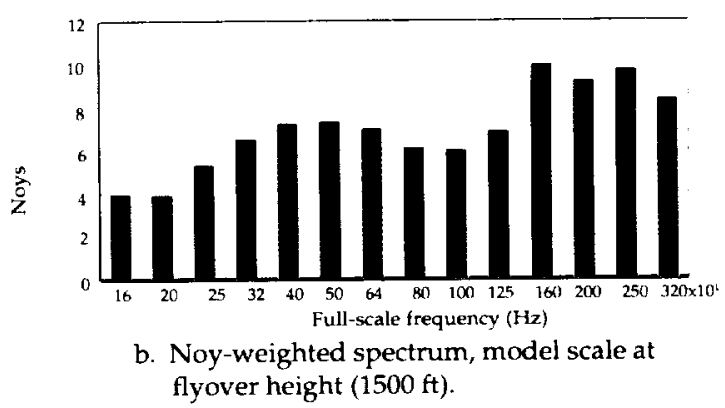

Figure 7 - Typical data with BPF-related tones removed, used to design broadband liner. 
Baseline (relative EPNL)

Relative EPNL with BPF tone removed

dB

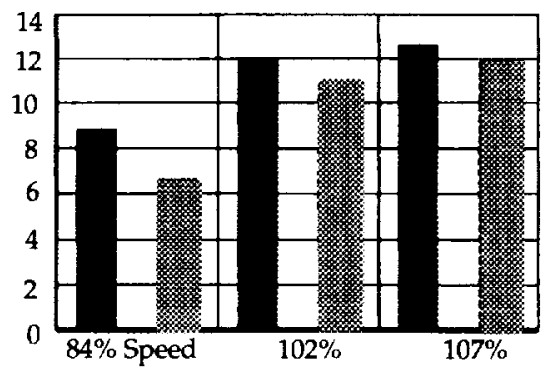

a. 40-vane model, long inlet.

$\mathrm{dB}$

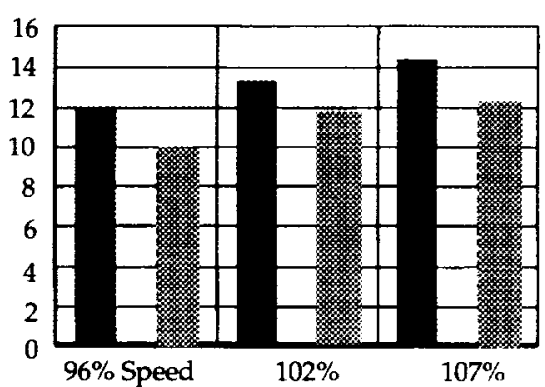

b. 40-vane model, midlength inlet.

$\mathrm{dB}$

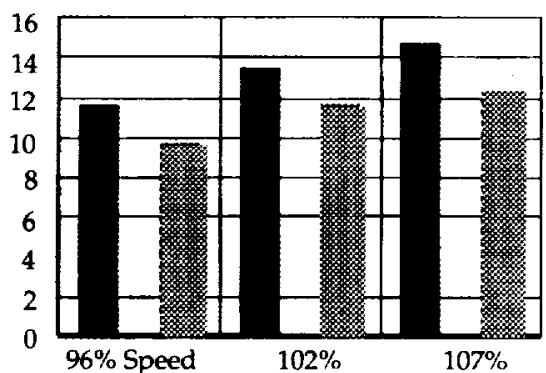

c. 40-vane model, short inlet.
$\mathrm{dB}$

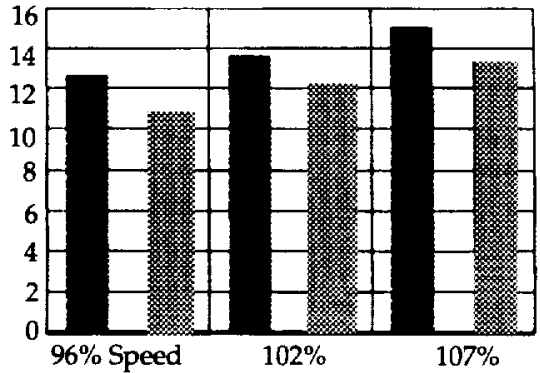

d. 40-vane model, short inlet, long spinner.

$\mathrm{dB}$

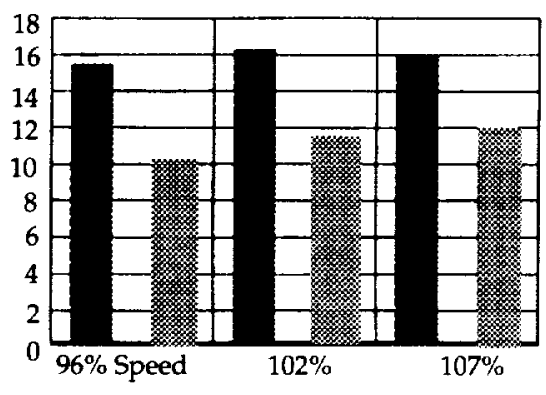

e. 22-vane model, long inlet.

dB

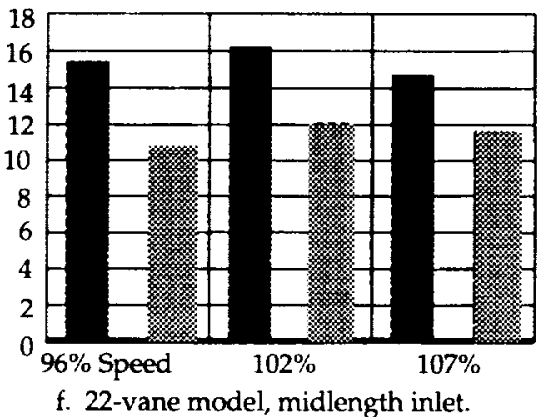

$\mathrm{dB}$

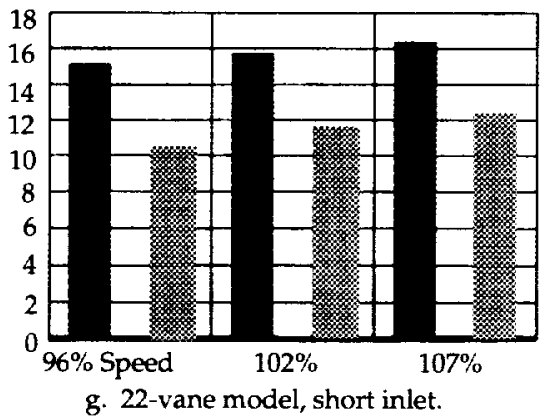

Figure 8 - Relative effect of BPF tone removal on EPNL. 
Baseline (relative EPNL)

Liner at BPF

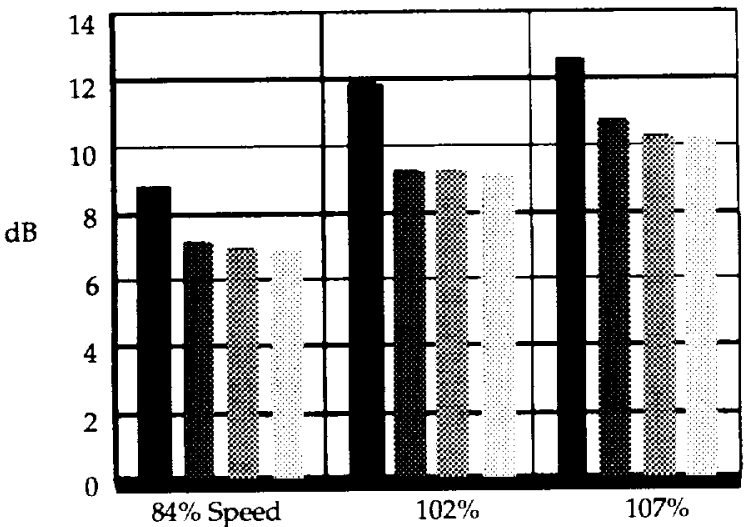

a. 40-vane model, long inlet.

$\mathrm{dB}$

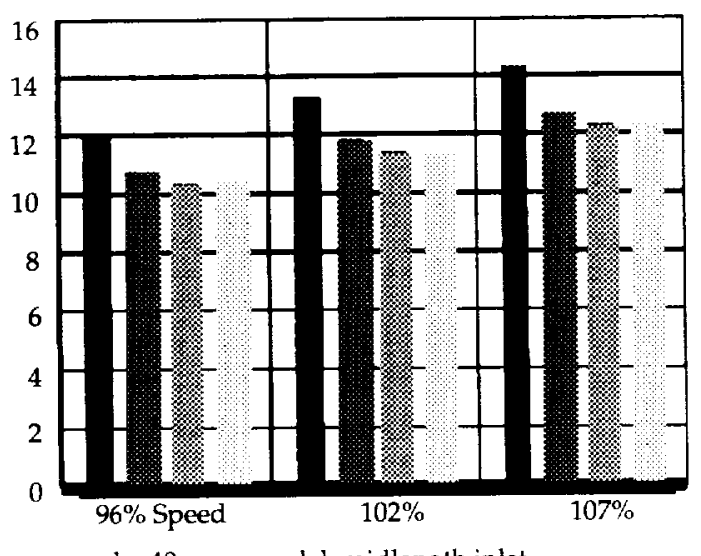

b. 40-vane model, midlength inlet.

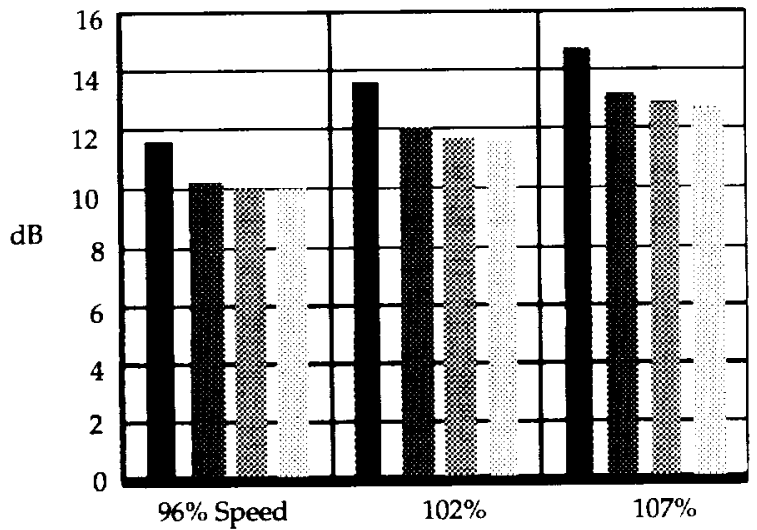

c. 40-vane model, short inlet.
Liner at 2BPF

$\square$ Liner optimized for broadband

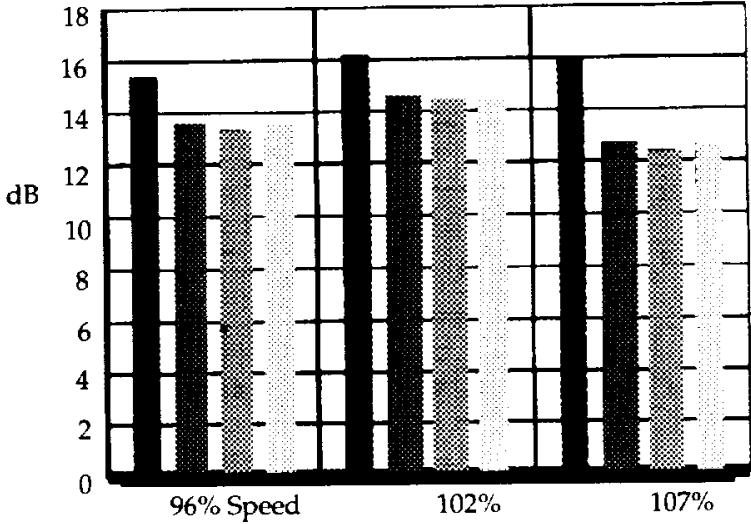

d. 22-vane model, long inlet.
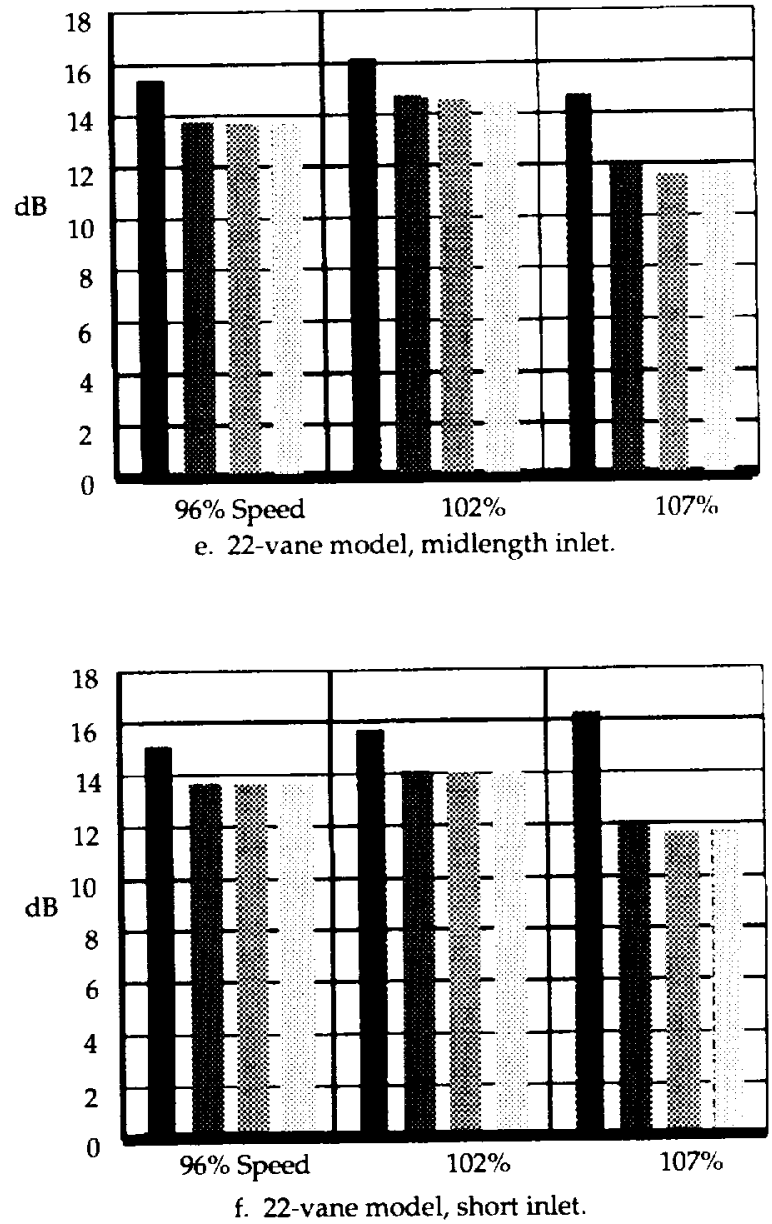

Figure 9 - Relative effect of simulated exhaust duct liner on EPNL. 
Baseline (no simulated noise control).

BPF removed

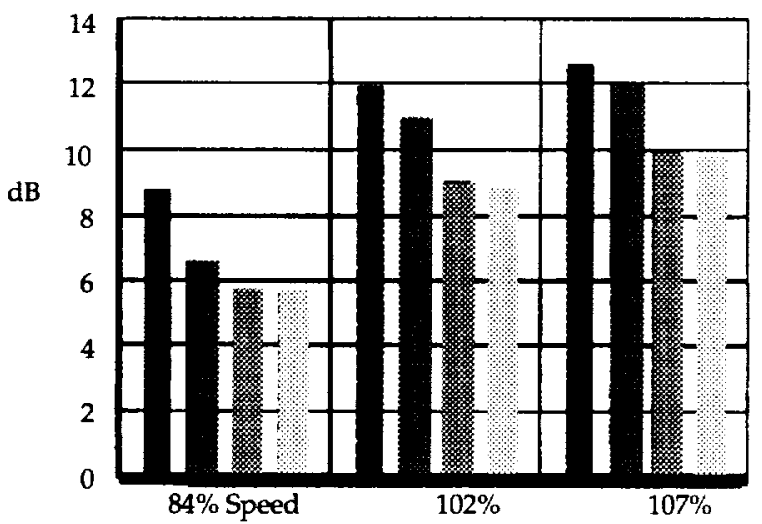

a. 40-vane model, long inlet.

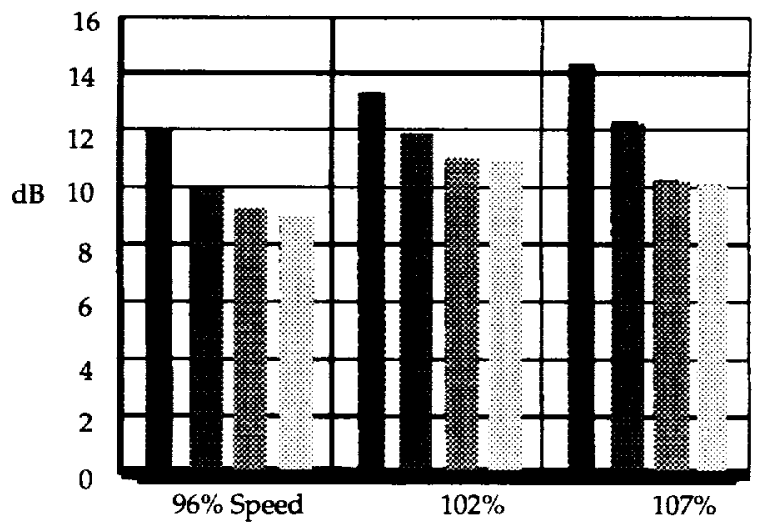

b. 40-vane model, midlength inlet.

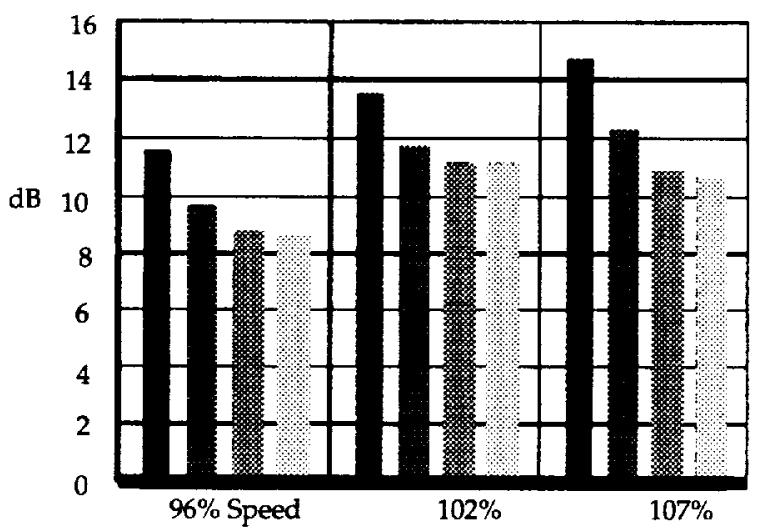

c. 40-vane model, short inlet.
BPF removed + liner at 2BPF

BPF removed + broadband liner

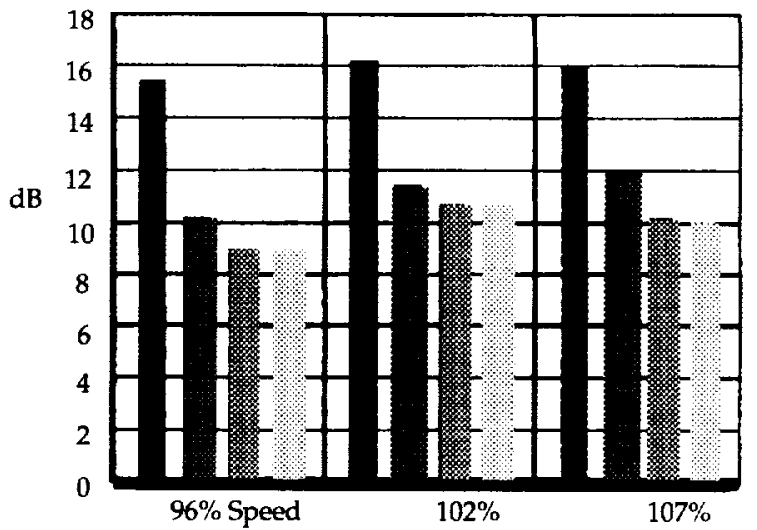

d. 22-vane model, long inlet.
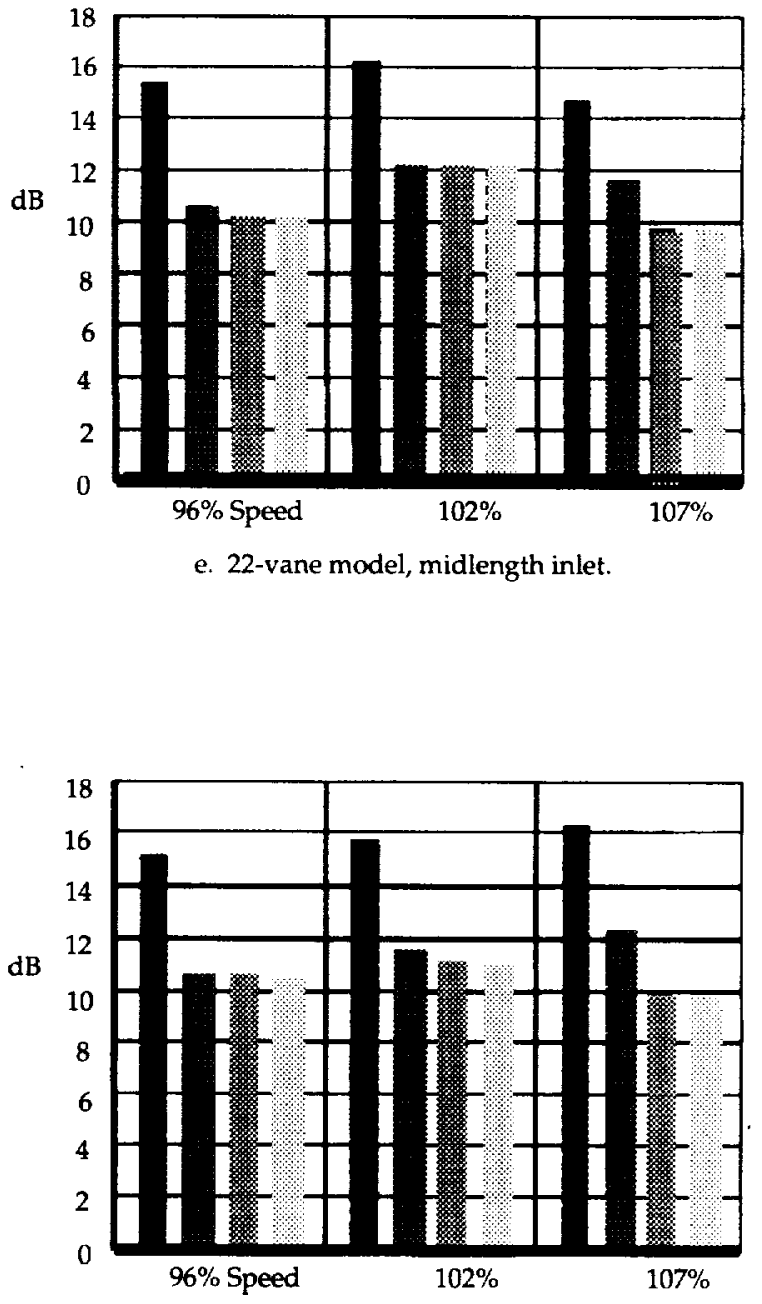

f. 22-vane model, short inlet.

Figure 10 - Relative effect of active noise control versus active-passive hybrid noise control on EPNL. 


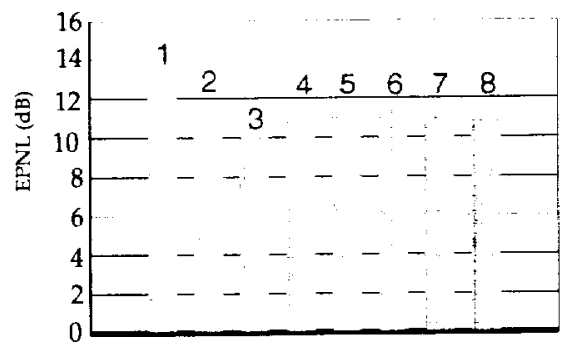

1 Baseline (no noise control)

2 BPF removed

3 All tones removed

4 Liner at BPF

5 Liner at 2 BPF

6 Liner tuned for broadband

7 ANC + liner at 2 BPF

8 ANC + broadband liner

a. 40-vane model

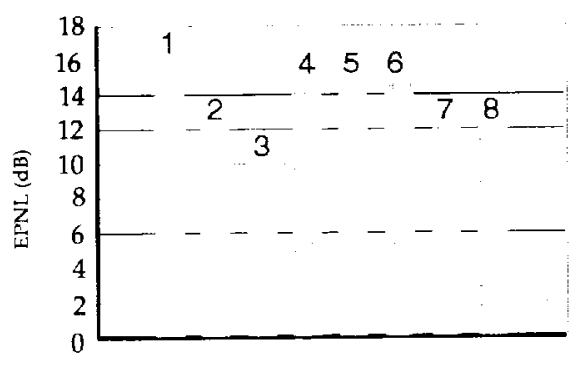

b. 22-vane model

Figure 11 - Relative effect of all simulated noise control measures on EPNL for midlength inlet; $102 \%$ speed. 
Baseline (all tones present)

\section{All BPF-related tones removed}

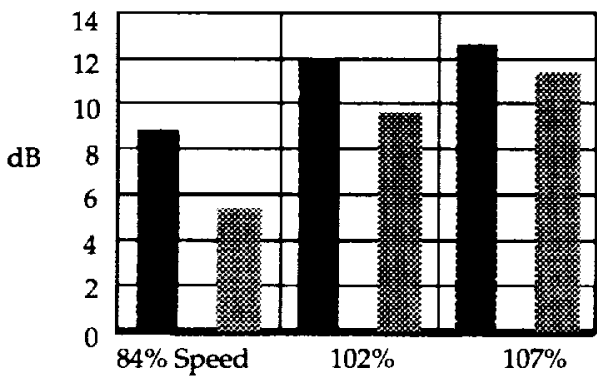

a. 40-vane model, long inlet

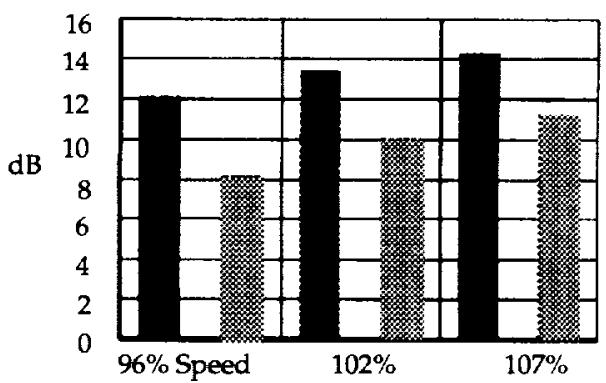

b. 40-vane model, midlength inlet

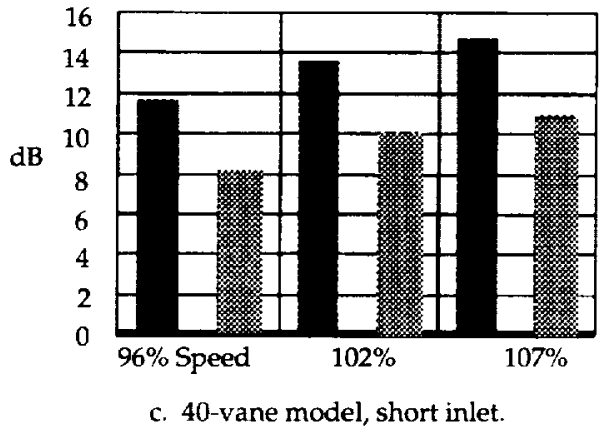

dB

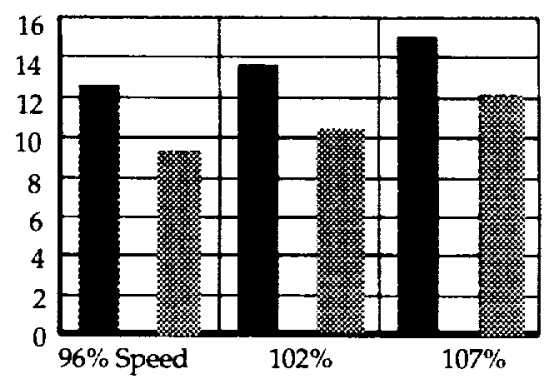

d. 40-vane model, short inlet, long spinner.

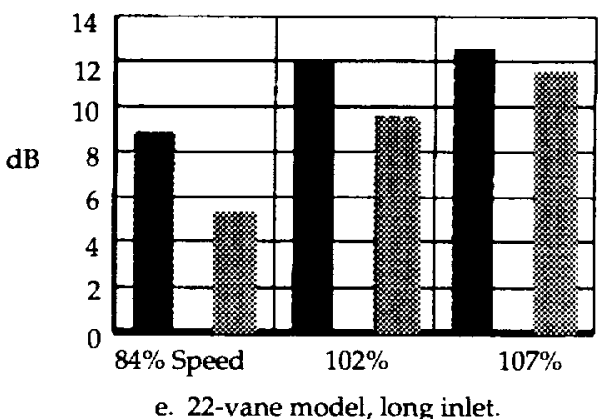

dB

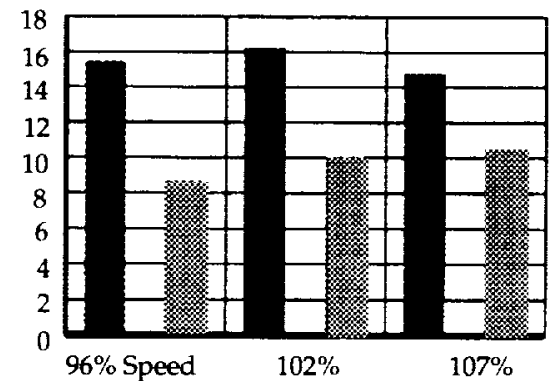

f. 22-vane model, midlength inlet.

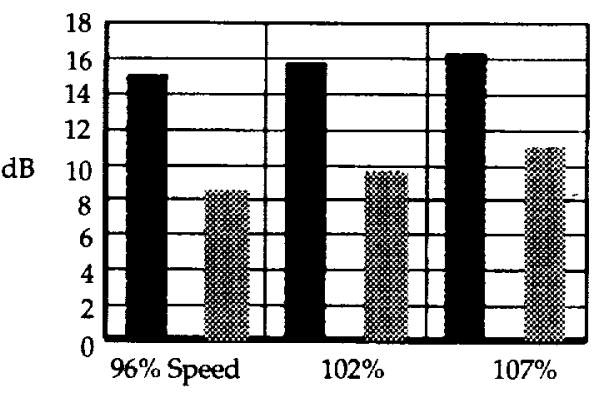

g. 22-vane model, short inlet.

Figure 12 - Relative contribution of broadband noise to EPNL. 


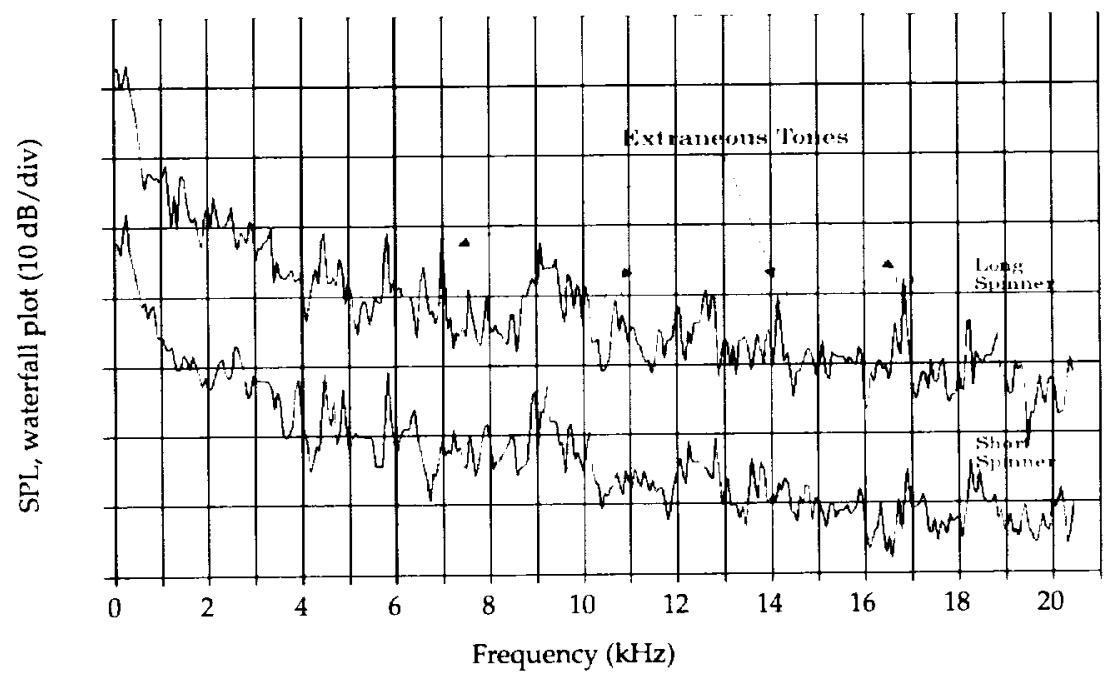

Figure 13 - Comparison of long versus short spinners with the BPF and harmonics removed for the 40-vane model operating at $102 \%$ speed; short inlet. 
Public reporting burden for this coltection of information is estimated to average 1 hour per response, including the time for reviewing instructions, searching existing data sources, gathering and maintaining the data needed, and completing and reviewing the collection of information. Send comments regarding this burden estimate or any other aspect of this collection of information, including suggestions for reducing this burden, to Washington Headquarters Services, Directorate for Intormation Operations and Reports, 1215 Jefferson Davis Highway, Suite 1204, Arlington, VA 22202-4302, and to the Office of Management and Budget, Papenwork Reduction Project (0704-0188), Washington, DC 20503.

\begin{tabular}{|l|c|r|}
\hline 1. AGENCY USE ONLY (Leave blank) & $\begin{array}{r}\text { 2. REPORT DATE } \\
\text { October } 1993\end{array}$ & $\begin{array}{r}\text { 3. REPORT TYPE AND DATES COVERED } \\
\text { Technical Memorandum }\end{array}$ \\
\hline
\end{tabular}

4. TITLE AND SUBTITLE

5. FUNDING NUMBERS

Noise Levels From a Model Turbofan Engine With Simulated Noise Control

Measures Applied

6. AUTHOR(S)

WU-535-03-10

David G. Hall and Richard P. Woodward

7. PERFoRming ORganization NAME(S) AND ADDRESS(ES)

National Aeronautics and Space Administration

Lewis Research Center

Cleveland, Ohio 44135-3191

8. PERForming ORGANIZATION REPORT NUMBER

E-8063

9. SPONSORINGMONITORING AGENCY NAME(S) AND ADDRESS(ES)

10. SPONSORINGMONITORING AGENCY REPORT NUMBER

National Aeronautics and Space Administration

Washington, D.C. 20546-0001

NASA TM- 106318

AIAA-93-4401

11. SUPPLEMENTARY NOTES

Prepared for the 15th AIAA Aeroacoustics Conference sponsored by the American Institute of Aeronautics and Astronautics, Long Beach, California, October 25-27, 1993. David G. Hall, Sverdrup Technology, Inc. Lewis Research Center Group, 2001 Aerospace Parkway, Brook Park, Ohio 44142 and Richard P. Woodward, NASA Lewis Research Center. Responsible person, Richard P. Woodward, (216) 433-3923.

128. DISTRIBUTION/AVAILABILITY STATEMENT

12b. DISTRIBUTION CODE

Unclassified - Unlimited

Subject Categories 07 and 71

13. ABSTRACT (Maximum 200 words)

This paper presents a study of estimated full-scale noise levels based on measured levels from the Advanced Ducted Propeller (ADP) sub-scale model. Testing of this model was performed in the NASA Lewis Low Speed Anechoic Wind Tunnel at a simulated takeoff condition of Mach 0.2. Effective Perceived Noise Level (EPNL) estimates for the baseline configuration are documented in this report, and also used as the control case in a study of the potential benefits of two categories of noise control. The effect of active noise control is evaluated by artificially removing various rotor-stator interaction tones. Passive noise control is simulated by applying a notch filter to the wind tunnel data. Cases with both techniques are included to evaluate hybrid active-passive noise control. The results for EPNL values are approximate because the original source data was limited in bandwidth and in sideline angular coverage. The main emphasis is on comparisons between the baseline and configurations with simulated noise control measures.

\section{SUBJECT TERMS}

Ducted fan noise; Active noise control 15. NUMBER OF PAGES

fan noise; Active noise control

\begin{tabular}{|c|c|}
\hline $\begin{array}{c}\text { 17. SECURITY CLASSIFICATION } \\
\text { OF REPORT } \\
\text { Unclassified }\end{array}$ & $\begin{array}{c}\text { 18. SECURITY CLASSIFICATION } \\
\text { OF THIS PAGE } \\
\text { Unclassified }\end{array}$ \\
\hline
\end{tabular}

19. SECURITY CLASSIFICATION OF ABSTRACT Unclassified

Unclassified

15

16. PRICE CODE

$\mathrm{A03}$

\section{LIMITATION OF ABSTRACT}

